Байкальский государственный университет, г. Иркутск, Российская Федерация

П. Г. Сорокина

Байкальский государственный университет, г. Иркутск, Российская Федерация

\title{
МОДЕЛИРОВАНИЕ ПРОЦЕССОВ УБЫТКОВ СТРАХОВЩИКА С ПОМОЩЬЮ ВЕРОЯТНОСТНЫХ РАСПРЕДЕЛЕНИЙ НА ПРИМЕРЕ СТРАХОВОЙ КОМПАНИИ РОСГОССТРАХ
}

\begin{abstract}
АНнотАция. Данная работа посвящена моделированию размеров требований о выплате отдельным регионам по добровольному и обязательному страхованию (кроме обязательного медицинского страхования), которые производились страховой компанией РОСГОССТРАХ в 2016 году. В статье отчетные данные РОСГОССТРАХ аппроксимированы следующими вероятностными законами: экспоненциальное распределение, распределение Парето, гамма-распределение (распределение Эрланга), логнормальное распределение. Для каждого класса распределений решена задача оценивания неизвестных параметров с помощью методов максимального правдоподобия и моментов. Качество подгонки всех простроенных моделей протестировано с помощью критерия согласия Пирсона. Для вычисления теоретически ожидаемых частот, сводных характеристик выборки, наблюдаемого и критического значений критерия, построения графиков была использована программа Microsoft Excel. В результате исследования установлено, что распределение убытков страховой компании РОСГОССТРАХ лучше всего описывается логнормальной моделью с оцененными параметрами.
\end{abstract}

кЛЮЧЕВЫЕ слоВА. Страховая компания РОСГОССТРАХ; размер выплат; распределение потерь; метод максимального правдоподобия; метод моментов; критерий согласия.

ИНФОРМАЦИЯ О СТАТЬЕ. Дата поступления 30 октября 2017 г.; дата принятия к печати 19 декабря 2017 г.; дата онлайн-размещения 29 декабря 2017 г.

O.V. Leonova

Baikal State University, Irkutsk, Russian Federation

P.G. Sorokina

Baikal State University, Irkutsk, Russian Federation

\section{DMODELING THE INSURER'S LOSSES PROCESSES WITH THE HELP OF PROBABILITY DISTRIBUTIONS IN TERMS OF ROSGOSSTRAKH INSURANCE COMPANY}

\begin{abstract}
The article is devoted to modeling amounts of payment requirements of certain regions on a voluntary and obligatory insurance (except of the obligatory medical insurance), which were made by ROSGOSSTRAKH insurance company in 2016. The reporting data of ROSGOSSTRAKH in the article is approximated by the following probabilistic laws: exponential distribution, Pareto distribution, gamma distribution (Erlang distribution), lognormal distribution. The problem of estimating the unknown parameters for each class of distributions is solved by using methods of the highest likelihood and moments. The quality of fitting all the constructed models is tested using Pearson's fitting criterion. The Microsoft Excel program is used to calculate the theoretically expected frequencies, the multiple sample characteris-
\end{abstract}

\section{Baikal Research Journal}


tics, the observed and critical values of the criterion, and the charts construction. The research results determine that the distribution of losses of ROSGOSSTRAKH insurance company is best of all described by the lognormal model with estimated parameters.

KEYWORDS. ROSGOSSTRAKH insurance company; amount of payments; loss distribution; highest likelihood technique; method of fitting moments; fitting criterion.

ARTICLE INFO. Received October 30, 2017; accepted December 19, 2017; available online December 29, 2017.

Страхование - одна из активных сфер современного бизнеса, которая динамично развивается; оно органически встроено в систему рыночных экономических отношений, а объемы операций на рынке страховых услуг стремительно возрастают. Все это свидетельствует о повышении роли и места страхования в современной экономике. На сегодняшний день известно достаточно большое количество моделей, описывающих деятельность страховых компаний. Так в статье [1] авторы проводят обзор и анализ особенностей страховых рисков, исследование существующих подходов, методов и моделей для описания и оценивания таких рисков. Показано, что существует множество методов оценивания рисков в страховании, в частности экспертные, тарификационные, математические и статистические методы. Установлено, что вероятностные модели дают возможность получить более высокое качество оценок прогнозов возможных потерь страховщика. В работах $[2 ; 3 ; 4]$ разрабатываются методы прогнозирования выплат и анализ ошибок такого прогнозирования. В работе [5] предлагается аппроксимация статистических данных аналитическими законами.

Для правильного управления страховой компанией фундаментальное значение имеет информация об общем размере требований о выплате за определенный период времени. Рассмотрим одну из составляющих общего размера требований о выплате - размер требований о выплате регионам. Предполагается, что указанные размеры требований описываются специальными распределениями, называемыми распределениями потерь (убытков) [3].

Обычно предполагается, что распределение требований о выплате находится в некотором классе распределений. К таким распределениям относятся:

- экспоненциальное распределение $X \sim E(\lambda)$,

- распределение Парето $X \sim P(\alpha, \lambda)$,

- гамма-распределение $X \sim G(k, \theta)$,

- логнормальное распределение $X \sim L N(\mu, \sigma)$.

Тогда возникает задача оценки параметров [6], от которых зависят эти распределения. Эти оценки определяются с помощью данных о требованиях страховых выплат и статистических методов оценивания параметров (например, метода моментов или метода максимального правдоподобия). При решении описанных задач могут возникнуть проблемы: например, из-за того, что размер требований о выплате ограничивается (перестрахование) или, потому, что нужно отсекать требования небольшого размера (франшиза).

Для построения выше перечисленных распределений будем использовать данные о размерах требований о выплате по 82 регионам, сделанных по некоторому виду страхования за 2016 год одной из крупнейшей страховой компанией - компанией «РОСГОССТРАХ» ${ }^{1}$. Размеры требований приведены в приложении и упорядочены для удобства работы с ними.

1 Страхование сегодня : профессиональный страховой портал. URL: http://www.insur-info.ru/ statistics $/$ ?unAction=region_comp\&comp_reg_num=1\&dir=out\&year=2016\&dec=4\&order=un $11 \&$ pair=za\#t.

\section{Baikal Research Journal}

электронный научный журнал Байкальского государственного университета 
Вычислим некоторые числовые характеристики выборки, приведенной в приложении:

- выброчное среднее $x=\frac{1}{n} \sum_{i=1}^{82} x_{i}=1187488,305$,

- исправленная дисперсия $S^{2}=\sqrt{\frac{n}{n-1} D_{B}}=4,402 \cdot 10^{12}$,

- среднее квадратическое отклонение $S=2098092,094$.

Частично сглаженные данные показаны на гистограмме (очень большие требования опущены на гистограмме).

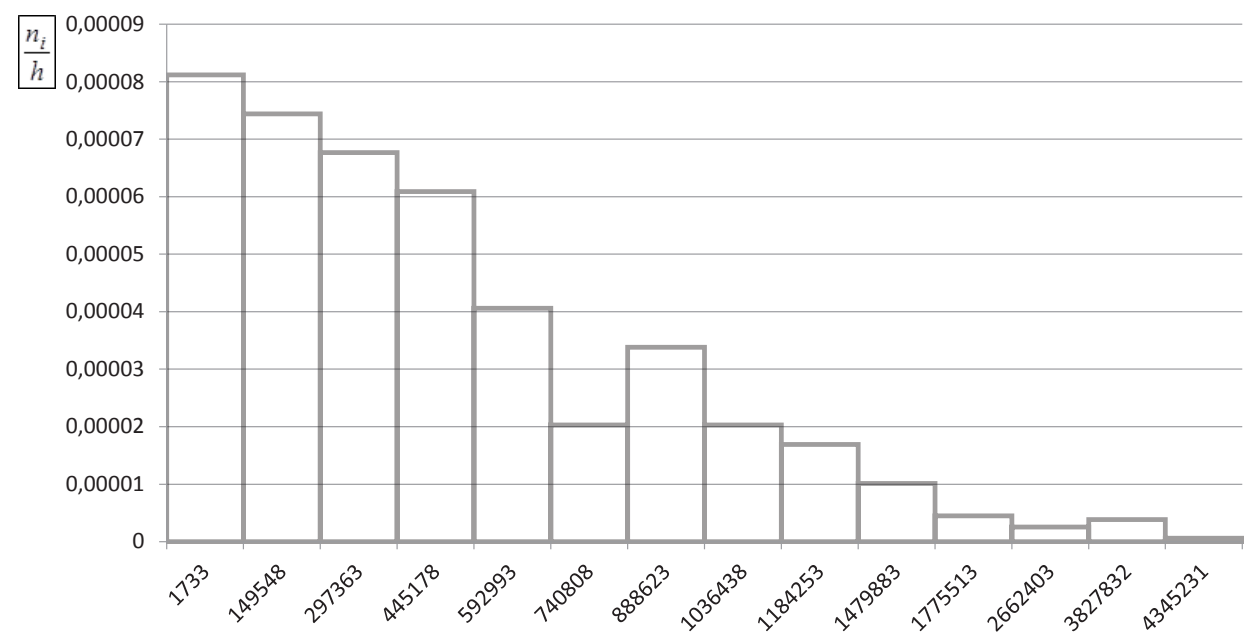

Рис. 1. Гистограмла размеров требований о выплате (по данныл приложения)

Аппроксимация эмпирических данных экспоненциальной моделью

По гистограмме на рис.1 можно предположить, что подходящее распределение должно быть асимметричным и «длиннохвостым». Одним из таких распределений является экспоненциальное распределение.

Выбрав класс экспоненциальных распределений, необходимо решить две задачи:

1) оценить параметры распределения;

2) проверить качество подгонки.

Для оценки параметра экспоненциального распределения будем использовать метод максимального правдоподобия [7].

Пусть размер отдельных требований о выплате - это случайная величина $X$, распределенная по экспоненциальному закону с плотностью

$$
p(x ; \lambda)=\lambda e^{-\lambda x}, x>0
$$

a $x_{1}, x_{2}, \ldots, x_{n}-$ независимые константы-наблюдения, т.е. значения случайной величины $X$.

Построим функцию правдоподобия:

$$
L(\lambda)=\prod_{i=1}^{82} p\left(x_{i} ; \lambda\right)=\prod_{i=1}^{82} \lambda e^{-\lambda x_{i}}=\lambda^{n} e^{-\lambda \sum_{i=1}^{82} x_{i}} .
$$

\section{Baikal Research Journal}


Соответствующая логарифмическая функция правдоподобия будет иметь вид:

$$
l(\lambda)=\ln L(\lambda)=n \ln \lambda-\lambda \sum_{i=1}^{82} x_{i}
$$

Продифференцируем полученную функцию по неизвестному параметру $\lambda$ и приравняем частную производную к нулю, получим уравнение правдоподобия:

$$
\frac{\partial l(\lambda)}{\partial \lambda}=\frac{n}{\lambda}-\sum_{i=1}^{82} x_{i}=0
$$

Решение этого уравнения и дает оценку неизвестного параметра

$$
\hat{\lambda}=\frac{n}{\sum_{i=1}^{82} x_{i}}=\frac{1}{x}=8,421 \cdot 10^{-7}
$$

Проведем тестирование подгонки, используя критерий согласия $\chi^{2}$ [8], для проверки гипотезы $H_{0}: X \sim E(\lambda)$ т.е. дадим формальный ответ на вопрос о близости подобранного экспоненциального распределения к эмпирическим данным.

Сгруппируем 82 наблюдения в 14 интервалов и установим ожидаемое число элементов в каждом интервале. Для определения теоретически ожидаемых частот воспользуемся средствами Microsoft Excel, результаты внесем в табл. 1.

Таблица 1

Элпирические и теоретически ожидаелые частоты (экспоненциальная модель)

\begin{tabular}{|l|c|c|}
\hline \multicolumn{1}{|c|}{ Интервалы } & Эмпирические частоты & $\begin{array}{c}\text { Теоретически ожидаемые } \\
\text { частоты }\end{array}$ \\
\hline $1733-149548$ & 12 & 9,5834553 \\
\hline $149548-297363$ & 11 & 8,4617877 \\
\hline $297363-445178$ & 10 & 7,4714023 \\
\hline $445178-592993$ & 9 & 6,5969338 \\
\hline $592993-740808$ & 6 & 5,8248149 \\
\hline $740808-888623$ & 3 & 5,1430663 \\
\hline $888623-1036438$ & 5 & 4,5411111 \\
\hline $1036438-1184253$ & 3 & 4,0096099 \\
\hline $1184253-1479883$ & 5 & 6,6662675 \\
\hline $1479883-1775513$ & 3 & 5,1971199 \\
\hline $1775513-2662403$ & 4 & 9,6732057 \\
\hline $2662403-3827832$ & 3 & 5,4467365 \\
\hline $3827832-4345231$ & 2 & 1,1531504 \\
\hline $4345231-14604306$ & 6 & 2,111382 \\
\hline Итого & 82 & 81,880043 \\
\hline
\end{tabular}

Определим наблюдаемое значение критерия $\chi_{0}^{2}=\sum_{i=1}^{14} \frac{\left(n_{i}-n p_{i}\right)^{2}}{n p_{i}}=17,856$. Найдем критическую точку как квантиль распределения $\chi^{2}$ с вероятностью 0,95 и чис-

\section{Baikal Research Journal}


лом степеней свободы $\mathrm{k}-2=12, \chi_{k p}^{2}=21,02607$. Поскольку $\chi_{0}^{2}<\chi_{k p}^{2}$, то гипотеза $H_{0}: X \sim E(\lambda)$ принимается, т.е. случайная величина $X$ - размер отдельных требований о выплате распределена по экспоненциальному закону с параметром $\hat{\lambda}=8,421 \cdot 10^{-7}$.

По данным табл. 1 построим график подбора экспоненциального распределения эмпирическим данным.

эмпирические частоты теоретически ожидаемые частоты

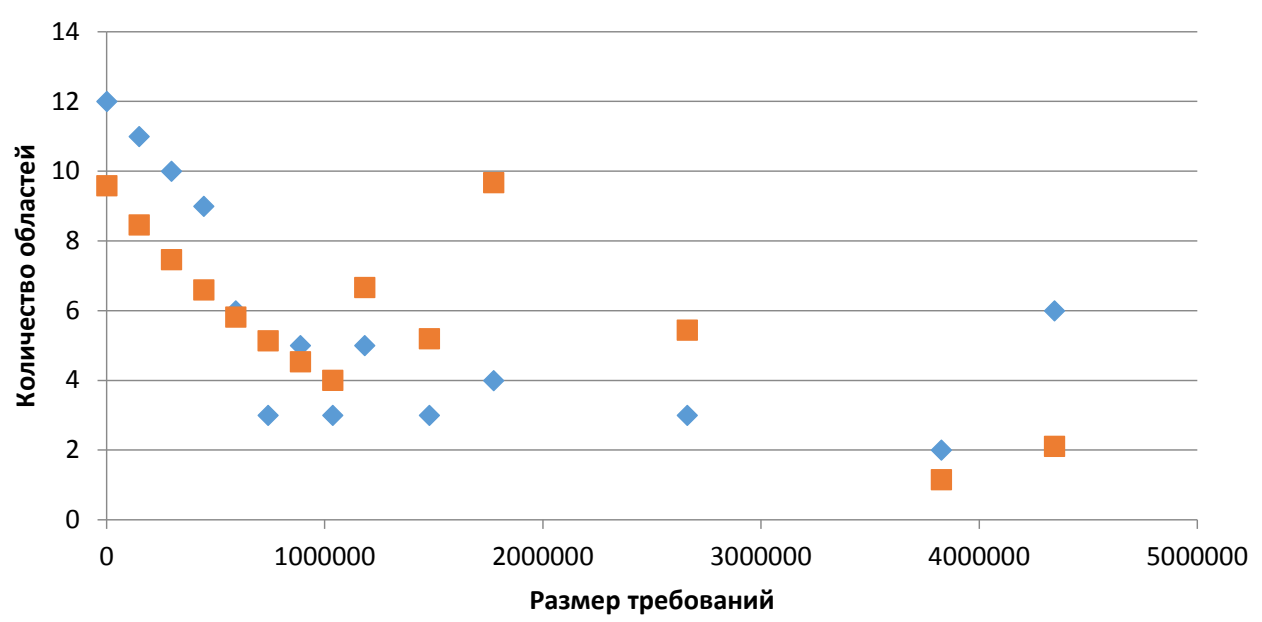

Рис. 2. График подбора экспоненциальной модели элпирическим данным

Рис. 2 показывает, что построенная модель не достаточно точно аппроксимирует исходные данные: требования размером до 500000 превышают подогнанные для них, а требования размером от 1500000 до 4000000, напротив, ниже подогнанных. Кроме того, очень большие требования превышают соответствующие модельные значения.

Результаты тестирования привели к необходимости подбора распределения, у которого бы «оба хвоста весили больше», чем у экспоненциального распределения. Таким распределением может служить распределение Парето.

\section{Аппроксимация эмпирических данных моделью Парето}

Предположим, что исследуемая случайная величина $X$ - размер отдельных требований о выплате распределена по закону Парето [9] с плотностью

$$
p(x ; \alpha, \lambda)=\frac{\alpha \lambda^{\alpha}}{(\lambda+x)^{\alpha+1}}, x>0 .
$$

Оценки параметров $\alpha$ и $\lambda$ распределения Парето найдем с помощью метода моментов [10] из системы уравнений, полученной приравниванием теоретических и эмпирических моментов:

$$
\left\{\begin{array}{c}
\frac{\lambda}{\alpha-1}=1187488,305, \\
\frac{\alpha \lambda^{2}}{(\alpha-1)^{2}(\alpha-2)}=4,402 \cdot 10^{12} .
\end{array}\right.
$$

\section{Baikal Research Journal}


Решение этой системы дает оценки неизвестных параметров

$$
\hat{\alpha}=2,942626387, \hat{\lambda}=2306832,517 \text {. }
$$

Чтобы определить качество подгонки модели Парето, используем критерий согласия $\chi^{2}$ для проверки гипотезы $H_{0}: X \sim P(\alpha, \lambda)$. Теоретически ожидаемые частоты определим из соотношения:

$$
n p_{i}=P\left(x_{i}<X<x_{i+1} / H_{0}\right)=F\left(x_{i+1}\right)-F\left(x_{i}\right),
$$

где

$$
F(x ; \alpha, \lambda)=1-\frac{\lambda^{\alpha}}{(\lambda+x)^{\alpha}}, x>0
$$

функция распределения Парето. Результаты анализа внесем в табл. 2.

Элпирические и теоретически ожидаемые частоты (модель Парето)

\begin{tabular}{|l|c|c|}
\hline \multicolumn{1}{|c|}{ Интервалы } & Эмпирические частоты & Теоретически ожидаемые частоты \\
\hline $1733-149548$ & 12 & 13,65732 \\
\hline $149548-297363$ & 11 & 10,76821 \\
\hline $297363-445178$ & 10 & 8,605966 \\
\hline $445178-592993$ & 9 & 6,961449 \\
\hline $592993-740808$ & 6 & 5,692549 \\
\hline $740808-888623$ & 3 & 4,700702 \\
\hline $888623-1036438$ & 5 & 3,916275 \\
\hline $1036438-1184253$ & 3 & 3,289244 \\
\hline $1184253-1479883$ & 5 & 5,154083 \\
\hline $1479883-1775513$ & 3 & 3,785033 \\
\hline $1775513-2662403$ & 4 & 6,715527 \\
\hline $2662403-3827832$ & 3 & 3,960943 \\
\hline $3827832-4345231$ & 2 & 0,977724 \\
\hline $4345231-14604306$ & 62 & 3,400634 \\
\hline Итого & & 81,58566 \\
\hline
\end{tabular}

Определим наблюдаемое значение критерия $\chi_{0}^{2}=5,849446$ и критическую точку $\chi_{k p}^{2}=19,67514$. Поскольку $\chi_{0}^{2}<\chi_{k p}^{2}$, то гипотеза $H_{0}: X \sim P(\alpha, \lambda)$ принимается, т.е. случайная величина $X$ - размер отдельных требований о выплате распределена по закону Парето с параметрами $\hat{\alpha}=2,942626387, \hat{\lambda}=2306832,517$.

По данным табл. 2 построим график подбора распределения Парето эмпирическим данным.

\section{Baikal Research Journal}




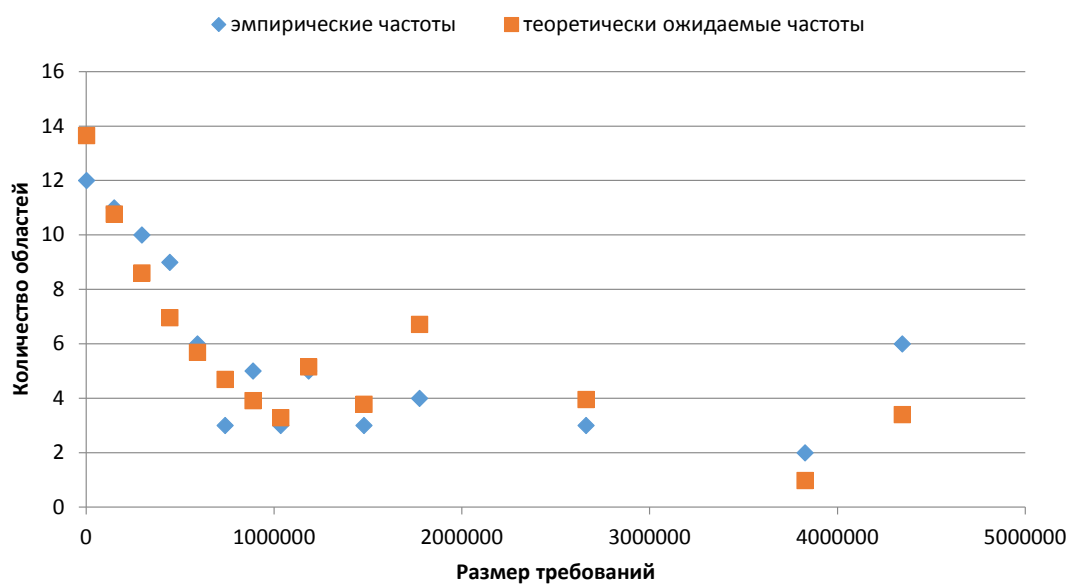

Рис. 3. График подбора лодели Парето элпирическил даннылм

Очевидно, что модель Парето дает хорошую подгонку и существенно улучшает экспоненциальную модель. Модель Парето лучше, чем экспоненциальная модель с позиции критерия $\chi^{2}$. Улучшение подгонки очевидно из рис. 3.

Аппроксимация эмпирических данных гамма-распределением

Предположим, что исследуемая случайная величина $X-$ размер отдельных требований о выплате распределена по гамма-закону с плотностью [11]

$$
p(x ; k, \theta)=\frac{x^{k-1} e^{-\frac{x}{\theta}}}{\Gamma(k) \theta^{k}}, x \geq 0 .
$$

Оценки параметров $k$ и $\theta$ гамма-распределения с использованием метода моментов будем находить из следующей системы уравнений:

$$
\left\{\begin{array}{l}
k \theta=1187488,305 \\
k \theta^{2}=4,402 \cdot 10^{12}
\end{array}\right.
$$

Решение этой системы дает оценки неизвестных параметров

$$
\hat{k}=0,320335, \hat{\theta}=3706998 .
$$

Для определения качества подгонки модели гамма-распределения используем критерий согласия $\chi^{2}$ для проверки гипотезы $H_{0}: X \sim G(k, \theta)$. Для определения теоретически ожидаемых частот воспользуемся средствами Microsoft Excel, peзультаты внесем в табл. 3.

Таблица 3

Эмпирические и теоретически ожидаемые частоты (гамма-распределение)

\begin{tabular}{|l|c|r|}
\hline \multicolumn{1}{|c|}{ Интервалы } & Эмпирические частоты & Теоретически ожидаемые частоты \\
\hline $1733-149548$ & 12 & 24,18206 \\
\hline $149548-297363$ & 11 & 7,640108 \\
\hline $297363-445178$ & 10 & 5,150467 \\
\hline $445178-592993$ & 9 & 3,938617 \\
\hline
\end{tabular}

\section{Baikal Research Journal}


Окончание табл. 3

\begin{tabular}{|l|c|r|}
\hline \multicolumn{1}{|c|}{ Интервалы } & Эмпирические частоты & Теоретически ожидаемые частоты \\
\hline $592993-740808$ & 6 & 3,194737 \\
\hline $740808-888623$ & 3 & 2,682403 \\
\hline $888623-1036438$ & 5 & 2,304094 \\
\hline $1036438-1184253$ & 3 & 2,011387 \\
\hline $1184253-1479883$ & 5 & 3,362253 \\
\hline $1479883-1775513$ & 3 & 2,71202 \\
\hline $1775513-2662403$ & 4 & 5,708838 \\
\hline $2662403-3827832$ & 3 & 4,414898 \\
\hline $3827832-4345231$ & 2 & 1,319941 \\
\hline $4345231-14604306$ & 6 & 5,883188 \\
\hline & 82 & 74,50501 \\
\hline
\end{tabular}

Определим наблюдаемое значение критерия $\chi_{0}^{2}=26,97197$ и критическую точку $\chi_{k p}^{2}=19,67514$. Поскольку $\chi_{0}^{2}<\chi_{k p}^{2}$, то гипотеза $H_{0}: X \sim G(k, \theta)$ отвергается, т.е. случайная величина $X$ - размер отдельных требований о выплате не распределена по гамма-закону с параметрами $\hat{k}=0,320335, \hat{\theta}=3706998$.

По данным табл. 3 построим график подбора гамма-распределения эмпирическим данным.

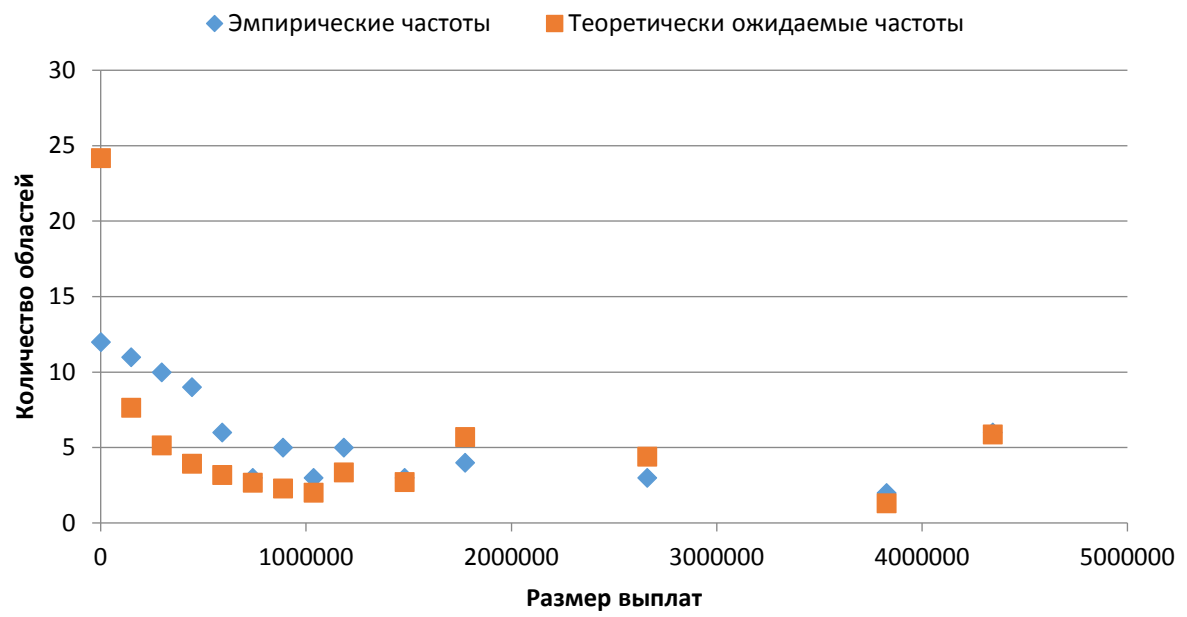

Рис. 4. График подбора галла-распределения элпирическил данныл

Рис. 4 показывает, что подгонка действительно плохая, т.к. требования малых размеров значительно ниже подогнанных, а требования размером от 150000 до 2000000, напротив, выше подогнанных.

\section{Аппроксимация эмпирических данных логнормальным распределением}

Предположим, что исследуемая случайная величина $X$ - размер отдельных требований о выплате распределена по логнормальному закону [12] с плотностью

\section{Baikal Research Journal}




$$
p(x ; \mu, \sigma)=\frac{1}{x \sigma \sqrt{2 \pi}} e^{-\frac{(\ln x-\mu)^{2}}{2 \sigma^{2}}}, \quad x, \sigma>0 \text {. }
$$

Оценки параметров $\mu$ и $\sigma$ логнормального распределения с использованием метода моментов будем находить из системы уравнений:

$$
\left\{\begin{array}{c}
e^{\mu+\frac{\sigma^{2}}{2}}=1187488,305 \\
\left(e^{\sigma^{2}}-1\right) e^{2 \mu+\sigma^{2}}=4,402 \cdot 10^{12}
\end{array}\right.
$$

Решение этой системы дает оценки неизвестных параметров

$$
\hat{\mu}=13,27920841, \hat{\sigma}=1,19007282 .
$$

Для определения качества подгонки модели логнормального распределения используем критерия согласия $\chi^{2}$ для проверки гипотезы $H_{0}: X \sim L N(\mu, \sigma)$. Для определения теоретически ожидаемых частот воспользуемся средствами Microsoft Excel, результаты внесем в табл. 4.

Таблица 4 Элпирические и теоретически ожидаемые частоты (логнормальное распределение)

\begin{tabular}{|l|c|r|}
\hline \multicolumn{1}{|c|}{ Интервалы } & Эмпирические частоты & Теоретически ожидаемые частоты \\
\hline $1733-149548$ & 12 & 10,1936 \\
\hline $149548-297363$ & 11 & 13,00452 \\
\hline $297363-445178$ & 10 & 10,21474 \\
\hline $445178-592993$ & 9 & 7,837785 \\
\hline $592993-740808$ & 6 & 6,097566 \\
\hline $740808-888623$ & 3 & 4,830908 \\
\hline $888623-1036438$ & 5 & 3,8936 \\
\hline $1036438-1184253$ & 3 & 3,186103 \\
\hline $1184253-1479883$ & 5 & 4,857841 \\
\hline $1479883-1775513$ & 3 & 3,482849 \\
\hline $1775513-2662403$ & 4 & 6,087742 \\
\hline $2662403-3827832$ & 3 & 3,632868 \\
\hline $3827832-4345231$ & 2 & 0,921949 \\
\hline $4345231-14604306$ & 6 & 3,480949 \\
\hline & 82 & 81,72302 \\
\hline
\end{tabular}

Определим наблюдаемое значение критерия $\chi_{0}^{2}=5,807536$ и критическую точку $\chi_{k p}^{2}=19,67514$. Поскольку $\chi_{0}^{2}<\chi_{k p}^{2}$, то гипотеза $H_{0}: X \sim L N(\mu, \sigma)$ принимается, т.е. случайная величина $X$ - размер отдельных требований о выплате распределена по логнормальному закону с параметрами $\hat{\mu}=13,283884807, \hat{\sigma}=1,186167784$.

По данным табл. 4 построим график подбора логнормального распределения эмпирическим данным.

\section{Baikal Research Journal}




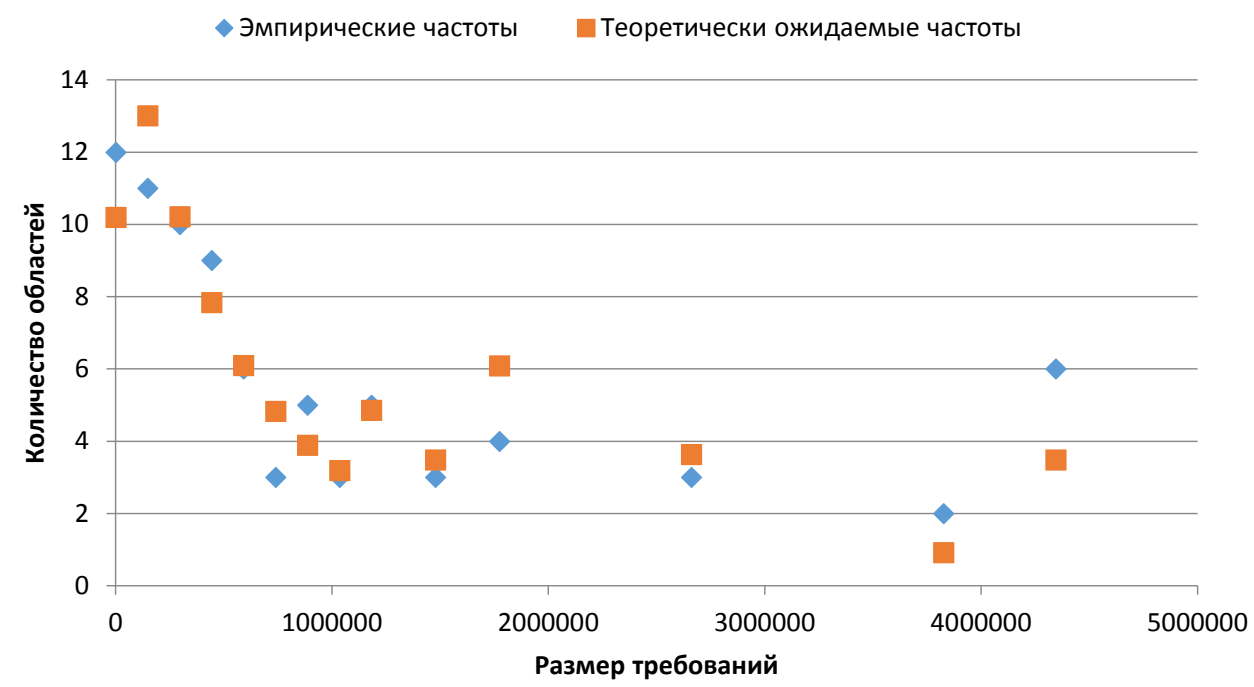

Рис. 5. График подбора логнормального распределения эмпирическим данным

Очевидно, что логнормальная модель дает лучшую подгонку и существенно улучшает ранее рассмотренные модели. Логнормальная модель чуть лучше, чем модель Парето и намного лучше экспоненциальной модели с позиции критерия $\chi^{2}$. Улучшение подгонки очевидно и из рис. 5 .

Таким образом, отчетные данные страховой компании «РОСГОССТРАХ» были аппроксимированы четырьмя законами. В результате исследования было установлено, что при моделировании потерь страховщика можно использовать следующих вероятностные распределения: экспоненциальное, Парето и логнормальное.

Проверка согласия экспериментальных данных с оцененными распределениями с помощью критерия $\chi^{2}$ позволила выбрать наилучшую модель - логнормальное распределение с параметрами $\hat{\mu}=13,28384807, \hat{\sigma}=1,186167784$

Эффективность деятельности страховой компании во многом зависит от того, насколько качественно организовано управление компанией. Полученные в работе результаты исследования могут в дальнейшем быть использованы для анализа и прогноза деятельности страховыми компаниями, поскольку описание убытков с помощью логнормальной модели может существенно упростить и улучшить анализ резервов риска, который требуется для возмещения убытков страховщика, что в итоге и обеспечивает финансовую устойчивость страховой компании.

Приложение

Выплаты по регионам за 2016 г. (в тыс. р.)

\begin{tabular}{|r|l|r|}
\hline № & \multicolumn{1}{|c|}{ Регион } & Итого (кроме обязат. мед страх.) \\
\hline 1 & Москва & 14604306 \\
\hline 2 & Краснодарский край & 9337092 \\
\hline 3 & Санкт-Петербург & 6411572 \\
\hline 4 & Республика Башкортостан & 4345231 \\
\hline 5 & Ростовская область & 4270701 \\
\hline 6 & Московская область & 3827832 \\
\hline
\end{tabular}

\section{Baikal Research Journal}

электронный научный журнал Байкальского государственного университета 
Продолжение прил.

\begin{tabular}{|c|c|c|}
\hline № & Регион & Итого (кроме обязат. мед страх.) \\
\hline 7 & Нижегородская область & 3812440 \\
\hline 8 & Свердловская область & 2778620 \\
\hline 9 & Республика Татарстан & 2576519 \\
\hline 10 & Волгоградская область & 2476002 \\
\hline 11 & Ставропольский край & 2305364 \\
\hline 12 & Самарская область & 1896589 \\
\hline 13 & Приморский край & 1677628 \\
\hline 14 & Челябинская область & 1669972 \\
\hline 15 & Пермский край & 1662333 \\
\hline 16 & Ивановская область & 1441393 \\
\hline 17 & Новосибирская область & 1341973 \\
\hline 18 & Иркутская область & 1338419 \\
\hline 19 & Оренбургская область & 1247292 \\
\hline 20 & Красноярский край & 1187618 \\
\hline 21 & Ульяновская область & 1180310 \\
\hline 22 & Воронежская область & 1173067 \\
\hline 23 & Липецкая область & 1090737 \\
\hline 24 & Саратовская область & 976981 \\
\hline 25 & Архангельская область без данных по Ненецкому АО & 972386 \\
\hline 26 & Белгородская область & 970994 \\
\hline 27 & Вологодская область & 951627 \\
\hline 28 & Ярославская область & 913984 \\
\hline 29 & $\begin{array}{l}\text { Тюменская область без данных по Ханты-Мансий- } \\
\text { ском АО }\end{array}$ & 877315 \\
\hline 30 & Кировская область & 799863 \\
\hline 31 & Ханты-Мансийский АО (Югра) & 767295 \\
\hline 32 & Пензенская область & 709726 \\
\hline 33 & Удмуртская Республика & 685254 \\
\hline 34 & Чувашская Республика - Чувашия & 679815 \\
\hline 35 & Владимирская область & 671674 \\
\hline 36 & Рязанская область & 633532 \\
\hline 37 & Амурская область & 631032 \\
\hline 38 & Республика Мордовия & 587877 \\
\hline 39 & Кемеровская область & 574650 \\
\hline 40 & Мурманская область & 561298 \\
\hline 41 & Республика Адыгея & 509070 \\
\hline 42 & Тульская область & 496522 \\
\hline 43 & Карачаево-Черкесская Республика & 467562 \\
\hline 44 & Калининградская область & 455179 \\
\hline 45 & Смоленская область & 451136 \\
\hline
\end{tabular}

\section{Baikal Research Journal}

электронный научный журнал Байкальского государственного университета 
Окончание прил.

\begin{tabular}{|c|c|c|}
\hline № & Регион & Итого (кроме обязат. мед страх.) \\
\hline 46 & Алтайский край & 449418 \\
\hline 47 & Ленинградская область & 432745 \\
\hline 48 & Брянская область & 417504 \\
\hline 49 & Тамбовская область & 399114 \\
\hline 50 & Калужская область & 394460 \\
\hline 51 & Тверская область & 386663 \\
\hline 52 & Республика Коми & 369878 \\
\hline 53 & Республика Бурятия & 355881 \\
\hline 54 & Республика Дагестан & 342202 \\
\hline 55 & Астраханская область & 338618 \\
\hline 56 & Кабардино-Балкарская Республика & 335099 \\
\hline 57 & Курская область & 320729 \\
\hline 58 & Республика Марий Эл & 316535 \\
\hline 59 & Хабаровский край & 293887 \\
\hline 60 & Томская область & 278084 \\
\hline 61 & Омская область & 264911 \\
\hline 62 & Республика Саха (Якутия) & 264459 \\
\hline 63 & Костромская область & 263349 \\
\hline 64 & Курганская область & 249389 \\
\hline 65 & Ямало-Ненецкий автономный округ & 226326 \\
\hline 66 & Республика Северная Осетия - Алания & 202021 \\
\hline 67 & Новгородская область & 183048 \\
\hline 68 & Забайкальский край & 182193 \\
\hline 69 & Псковская область & 174245 \\
\hline 70 & Камчатский край & 154097 \\
\hline 71 & Республика Карелия & 149548 \\
\hline 72 & Орловская область & 126090 \\
\hline 73 & Республика Хакасия & 99565 \\
\hline 74 & Республика Ингушетия & 93088 \\
\hline 75 & Республика Калмыкия & 82752 \\
\hline 76 & Сахалинская область & 70125 \\
\hline 77 & Республика Тыва & 61401 \\
\hline 78 & Еврейская автономная область & 46648 \\
\hline 79 & Магаданская область & 40203 \\
\hline 80 & Ненецкий автономный округ & 11410 \\
\hline 81 & Республика Алтай & 3221 \\
\hline 82 & Чукотский автономный округ & 1733 \\
\hline
\end{tabular}

\section{Baikal Research Journal}




\section{Список использованной литературы}

1. Боярова К. И. Классификация рисков в страховании и Байесовский подход к их анализу / К. И. Боярова, Е. Б. Лозова, П. И. Бидюк // Проблеми інформаційних технологій. - 2013. - № 1 (13). - С. 21-32.

2. Баскакова А. Оценка резервов произошедших, но незаявленных убытков по многомерным цензурированным данным страховой компании [Электронный ресурс] / А. Баскакова, B. Баскаков // Международная актуарная компания IAAC. - Режим доступа: http://iaac. $\mathrm{ru} /$ actual/otsenka-rezervov-proizoshedshikh-no-nezayavlennykh-ubytkov-po-mnogomernymtsenzurirovannym-dannym-st/.

3. Голоколосова Т. В. Прогнозирование и анализ технических резервов страховой компании / Т. В. Голоколосова, Е. А. Подгорная // Вестник Кемеровского государственного университета. - 2001. - № 3 (7). - С. 43-48.

4. Ерохин И. В. Качество прогнозирования произошедших, но незаявленных убытков / И. В. Ерохин // Системный анализ в проектировании и управлении : труды 10 Междунар. науч.-практ конф. - СПб. : СПбГПУ, 2006. - Вып. 2. - С. 99-103.

5. Леонова О. В. Аналитическая аппроксимация в личном страховании / Леонова О. В. // Проблемы и перспективы современной науки : 14 Международная научно-практическая конференция : сборник статей. - М., 2017. - С. 148-153.

6. Королев В. Ю. Математические основы теории риска / В. Ю. Королев, В. Е. Бенинг, С. Я. Шоргин. - М. : Физматлит, 2011. - 591 с.

7. Гмурман В. Е. Теория вероятностей и математическая статистика : учебное пособие / В. Е. Гмурман. - 12-е изд. - М. : Юрайт, 2014. - 478 с.

8. Эконометрика : учебник / ред. В. С. Мхитарян. - М. : Проспект, 2014. - 380 с.

9. Вентцель Е. С. Теория вероятностей / Е. С. Вентцель. - 4-е изд. - М. : Наука, 1969. - $576 \mathrm{c.}$

10. Колемаев В. А. Теория вероятностей и математическая статистика : учебник / В. А. Колемаев, В. Н. Калинина. - 3-е изд., перераб. и доп. - М. : Кнорус, 2017. - 367 с.

11. Балдин К. В. Теория вероятностей и математическая статистика : учебник / К. В. Балдин, В. Н. Башлыков, А. В. Рукосуев. - 2-е изд. - М. : Дашков и К, 2010. $473 \mathrm{c}$.

12. Гнеденко Б. В. Курс теории вероятностей : учебник / Б. В. Гнеденко. - Изд. 8-ое, испр. и доп. - М. : Едиториал УРСС, 2005. - 448 с.

\section{References}

1. Boyarova K. I., Lozova E. B., Bidyuk P. I. Classification of insurance risks and Bayesian approach to their analysis. Problemy informacijnyh tehnologij = Problems of Information Technologies, 2013, no. 1 (13), pp. 21-32. (In Ukrainian).

2. Baskakova A., Baskakov V. Reserve estimation of the losses that have occurred but not declared by use of multidimensional censored data of insurance company. Available at: http://iaac.ru/actual/otsenka-rezervov-proizoshedshikh-no-nezayavlennykh-ubytkov-po-mnogomernym-tsenzurirovannym-dannym-st/. (In Russian).

3. Golokolosova T. V., Podgornaya E. A. Forecast and analysis of technical reserves of insurance company. Vestnik Kemerovskogo gosudarstvennogo universiteta $=$ Bulletin of Kemerovo State University, 2001, no. 3 (7), pp. 43-48. (In Russian).

4. Erokhin I. V. Quality of forecasting the losses that have occurred but not declared. Sistemnyi analiz $v$ proektirovanii $i$ upravlenii. Trudy 10 Mezhdunarodnoi nauchno-prakticheskoi konferentsii [System analysis in design and management. Works of the $10^{\text {th }}$ International Scientific and Practical Conference]. Peter the Great St.Petersburg Polytechnic University Publ., 2006, vol. 2, pp. 99-103. (In Russian).

5. Leonova O. V. Analytical approximation in personal insurance. Problemy $i$ perspektivy sovremennoi nauki. 14 Mezhdunarodnaya nauchno-prakticheskaya konferentsiya [Problems and prospects of modern science. $14^{\text {th }}$ International Scientific and Practical Conference]. Moscow, 2017, pp. 148-153. (In Russian).

6. Korolev V. Yu., Bening V. E., Shorgin S. Ya. Matematicheskie osnovy teorii riska [Mathematical foundations of theory of risk]. Moscow, Fizmatlit Publ., 2011. 591 p.

\section{Baikal Research Journal}


7. Gmurman V. E. Teoriya veroyatnostei $i$ matematicheskaya statistika [Theory of Probability and Mathematical Statistics]. 12 $2^{\text {th }}$ ed. Moscow, Yurait Publ., 2014. 478 p.

8. Mkhitaryan V. S. (ed.). Ekonometrika [Econometrics]. Moscow, Prospekt Publ., 2014. $380 \mathrm{p}$.

9. Venttsel' E. S. Teoriya veroyatnostei [Theory of Probability]. $4^{\text {th }}$ ed. Moscow, Nauka Publ., 1969. $576 \mathrm{p}$.

10. Kolemaev V. A., Kalinina V. N. Teoriya veroyatnostei i matematicheskaya statistika [Theory of Probability and Mathematical Statistics]. $3^{\text {rd }}$ ed. Moscow, Knorus Publ., 2017. 367 p.

11. Baldin K. V., Bashlykov V. N., Rukosuev A. V. Teoriya veroyatnostei i matematicheskaya statistika [Theory of Probability and Mathematical Statistics]. $2^{\text {nd }}$ ed. Moscow, Dashkov i K. Publ., 2010. 473 p.

12. Gnedenko B. V. Kurs teorii veroyatnostei [Course of theory of probability]. $8^{\text {th }}$ ed. Moscow, Editorial URSS Publ., 2005. 448 p.

\section{Информация об авторах}

Леонова Ольга Васильевна - кандидат ф.-м. наук, доцент, кафедра математики и эконометрики, Байкальский государственный университет, 664003, г. Иркутск, ул. Ленина, 11, e-mail: olga.olgaleonova@yandex.ru.

Сорокина Полина Геннадьевна - старший преподаватель, кафедра математики и эконометрики, Байкальский государственный университет, 664003, Российская Федерация, г. Иркутск, ул. Ленина, 11. e-mail: ermolaeva_polina@mail.ru.

\section{Authors}

Olga V. Leonova - PhD Physics and Mathematics, Chair of Mathematics and Econometrics, Baikal State University, 11 Lenin St., 664003, Irkutsk; e-mail: olga.olgaleonova@yandex.ru.

Polina G. Sorokina - Senior Lecturer, Chair of Mathematics and Econometrics, Baikal State University, 11, Lenin St., 664003, Irkutsk; e-mail: ermolaeva_polina@mail.ru.

\section{Для цитирования}

Леонова О. В. Моделирование процессов убытков страховщика с помощью вероятностных распределений на примере страховой компании РОСГОССТРАХ / О. В. Леонова, П. Г. Сорокина // Baikal Research Journal. - 2017. - T. 8, № 4. - DOI: 10.17150/2411$\underline{6262.2017 .8(4)} .27$.

\section{For Citation}

Leonova O. V., Sorokina P. G. Modeling the insurer's loss processes with the help of probability distributions in terms of ROSGOSSTRAKH insurance company. Baikal Research Journal, 2017, vol. 8, no. 4. DOI: 10.17150/2411-6262.2017.8(4).27. (In Russian).

\section{Baikal Research Journal}

